\title{
" تقنيات الطلاء وأثرها على القيم الجمالية فى العمل النحتى "
}

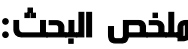

منذ القدم والمنحوتات فى مختلف العصور والحضسارات تتميز بملامسها وألوانها والتى تبرز جماليات أسطحها، وتختلف

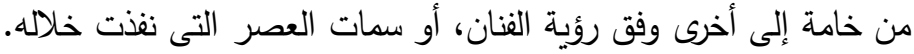

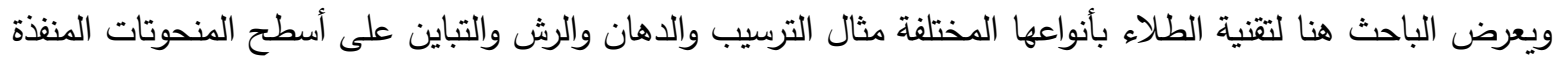
من خامة المعدن والمنفذة من خامة البوليستر •

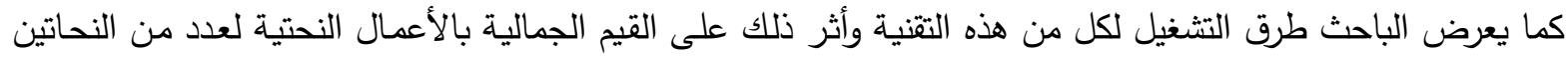

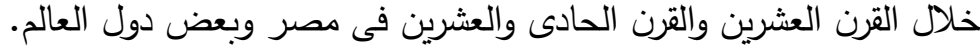

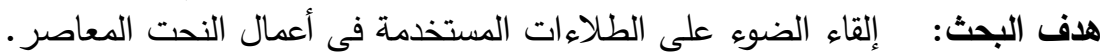

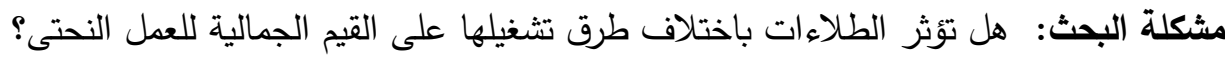
حدود البحث: الحدود الزمانية: القرن العشرين والقرن الواحد والعشرين.

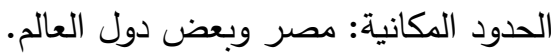
منهجية البحث: يتبع الباحث المنهج التاريخى التحليلى. كلمات مفتاحية: الترسيب - الايبوكسيمات - الأكاسيد.

هقدهة:

يؤكد التاريخ أن الطلاء كان موضـع اهتمام الثعوب جميعها خـلال الحقبة العديدة التى عاشتها البشرية والحقب مفتاحـا لمعرفة

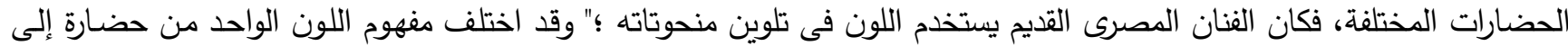

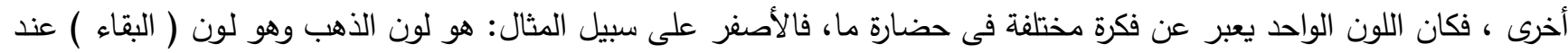

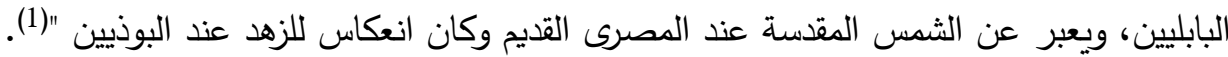

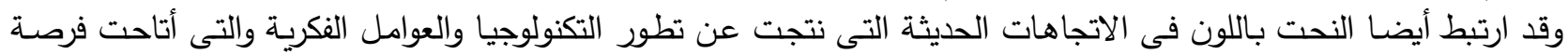

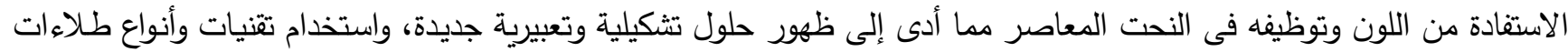

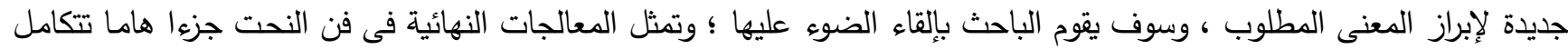

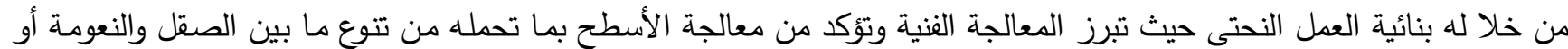

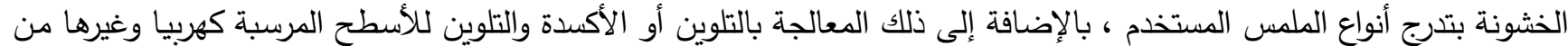

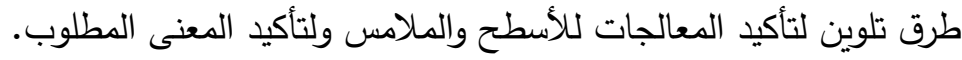
تعريف اللون: " اللون هو ذلك الأثر الذى تحدثه الموجات ذات أطوال والموجات الضوئية أو الترددات الضوئية المختلفة على عيوننا ؛ إن اللون

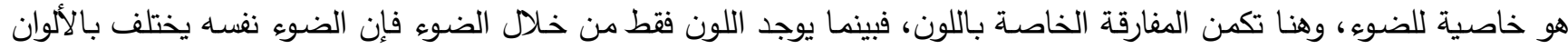

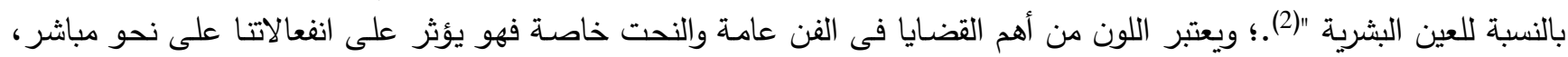

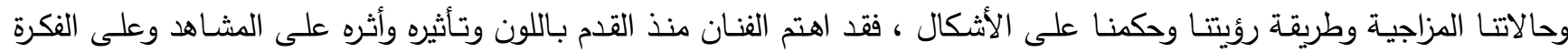

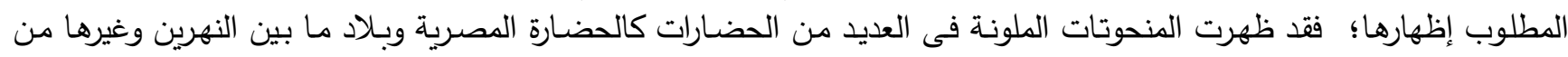

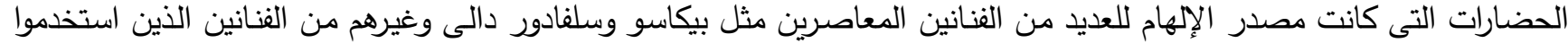

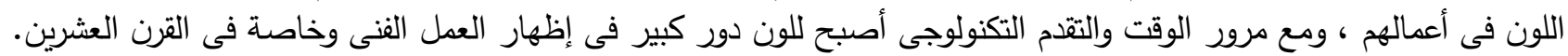

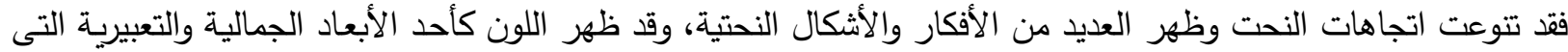

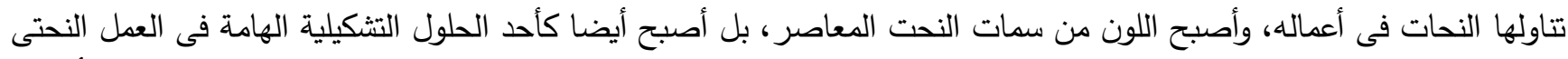

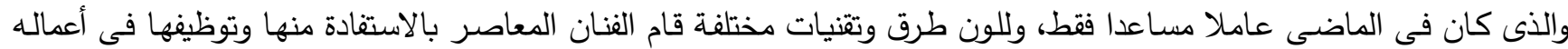

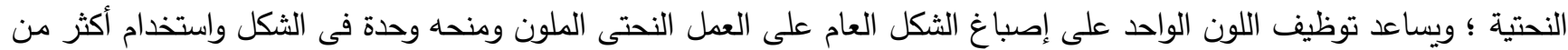

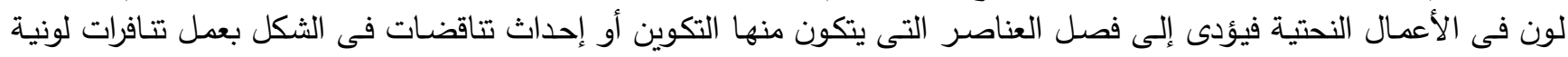
متوازية من الألوان بدرجاتها المختلفة. 
" التقنية هيى وسيلة او احدى الطرق المتبعة للتعبير فى الفن وهى مجموعة العمليات التى يمر بها أى عمل فنى حتى يصبح منتجا قائما بذاته.

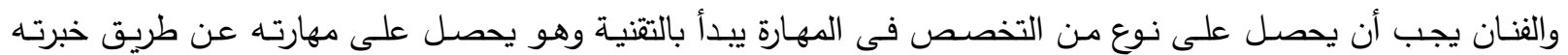

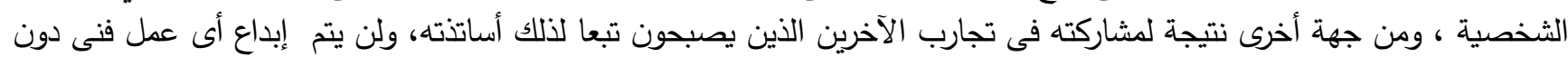

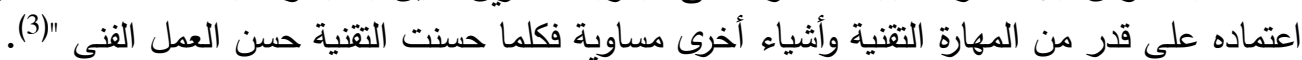

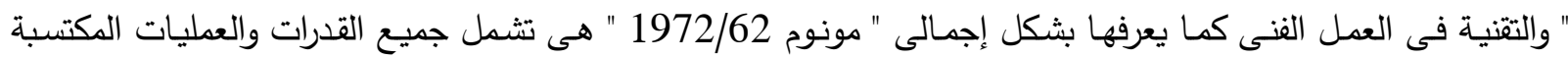

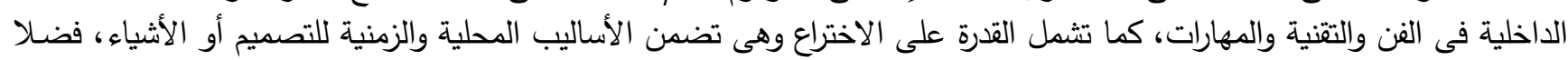

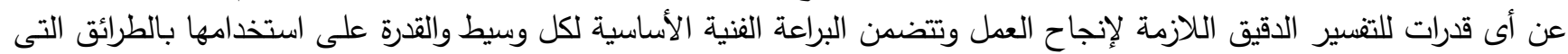

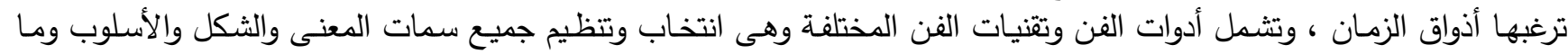

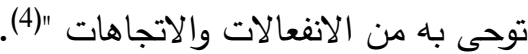

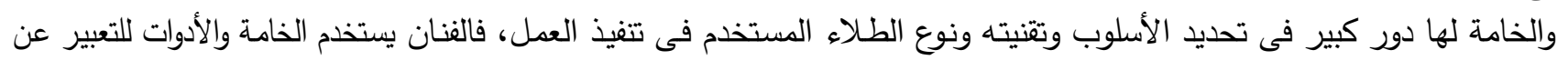

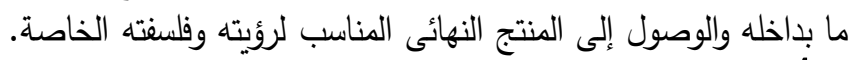

\section{أنواع الطlاع وطرق تلفيذها:}

ولال: بالترسيب:الطلاء

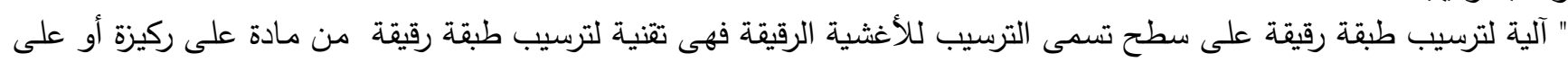

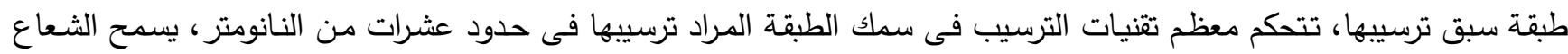

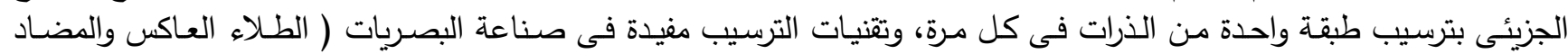

" لانعكاس ) " ويتلزم الطلاء من الناحية التطبيقية حسن اختيار المواد وسلامتها وقابليتها لتكون طبقة مناسبة، وهناك عدة وسائل لتغطية الأسطح

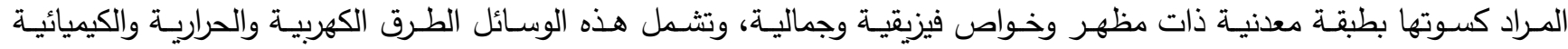

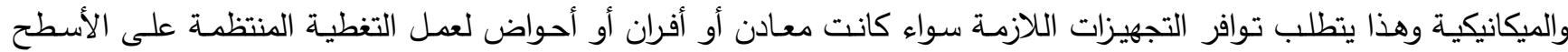

المعدنية"(5).

$$
\text { ومن هذه الأنواع: }
$$

1. الطلاء بالطرق الحراريـة وتمثل ( التكسية بالغدر في معدن منصـهر - والتكسية برزاز المعدن المصهور - الكسوة المعدنيـة الطلاء بتبخير المعدن ). 2. الطلاء بالطرق المائية وتثمل ( الطلاء بالتحليل الكهربى - الطلاء بالغمر أو الاحلال - الطلاء بالترسيب الكهربى ). أ- الطرق الحرارية:

1 وهى عملية تعتمد على مبادىه شديدة البساطة وهى من أقدم عمليات تكسية المعدن بمعدن آخر وتتلخص في في غمر القطعة المراد تكسيتها بالمعدن فى حمام من مصهور المعدن لمدة وجيزة، وبعد رفعها من الحمام تلتصق طبقة رقيقة من المعدن على سطحها ما دام

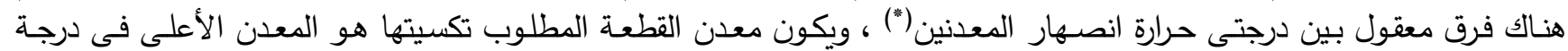
الانصهار (6)

$$
2
$$
يمكن رش المعادن القابلة للانصهار على السطح بونه بواسطة لهب غاز (الأوكسى استيلين)، ومن الناحية العلمية نجد أن الألومنيوم

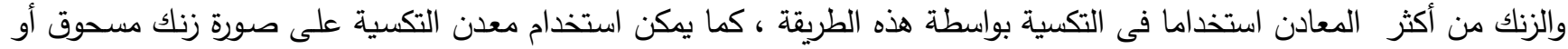

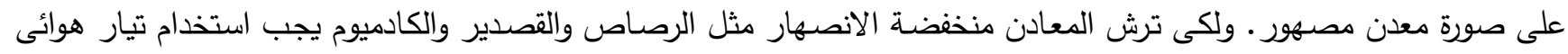
مضغوط من فوهة على المعدن المصهور باللهب لتصل ونل إلى السطح المراد تكسيته، حيث تقل درجة التصاق المعادن المصهورة المستخدمة بالمعدن الأساسى عنها فى الطلاء الكهربى.

3

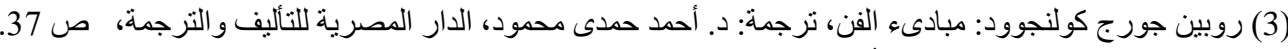

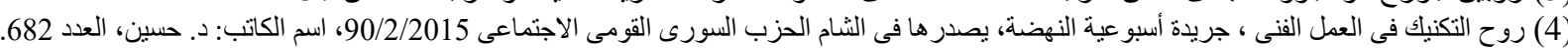
Langford, K.E.: Analysis of Electroplating and Related Solutions "Robert Dropar Hd., London, 1962. (5) (*) القطعة المر اد كسوتها بالمعدن الأصلى فى درجة الانصهار بحيث لا نقل عن 400 درجة مئوية، ووجود درجة حر ارة تزيد عن + 40 دار درجة مئوية. Langford, K.E.: Analysis of Electroplating and Related Solutions "Robert Dropar Hd., London, 1962. 
تعتمد هذه الطريقة على دهان وضغط مرتفع للمعدن المراد تغليفه بلوحين من المعدن الرقيق ، ويعد تغليف سبائك الزنك بالألومنيوم الأكثر شيوعا.

4 - الطلاء بتبخير المعدن:

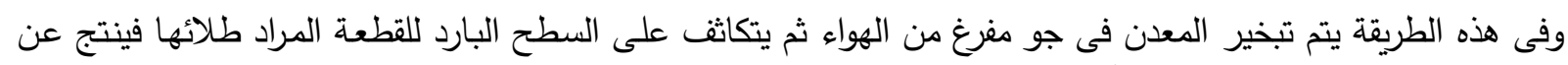
ذلك طبقة رقيقة للغاية ولا تصلح هذه الطبقة لأغراض الوقاية ولكنها تعتبر طبقة موصلة يمكن معها ترسيب مزيد من المعدن بطريقة

$$
\text { 1 الترسيب الكهربى. الطرق المائية: } 1
$$

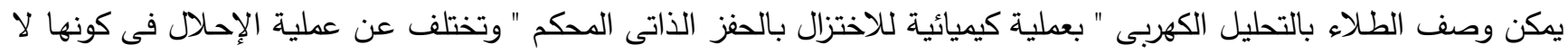

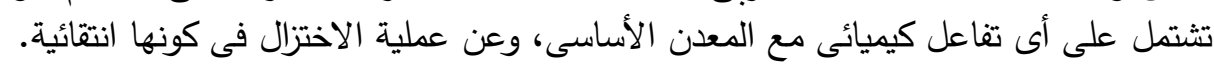

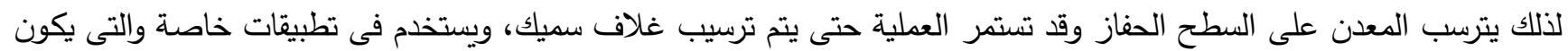

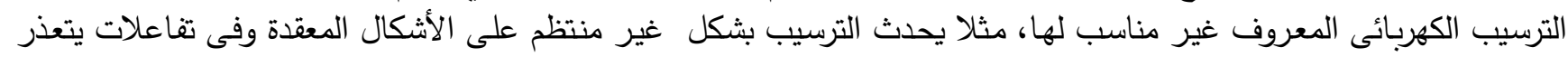

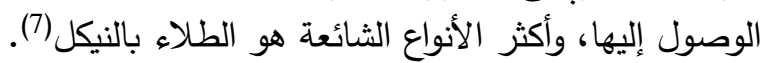
2

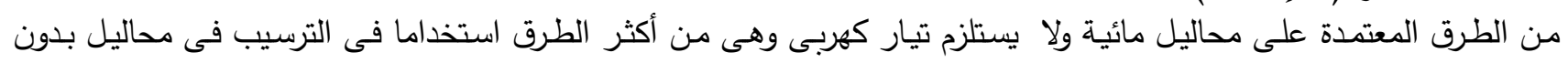

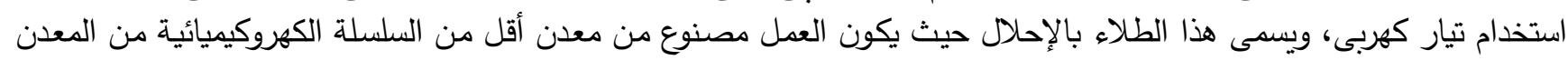

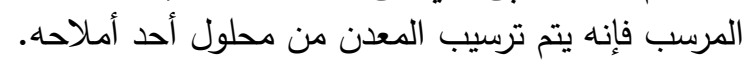

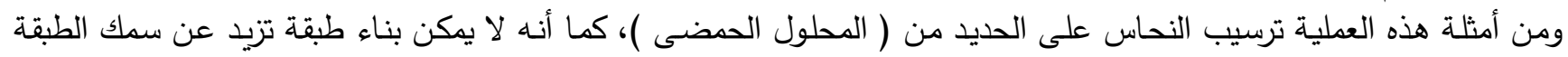

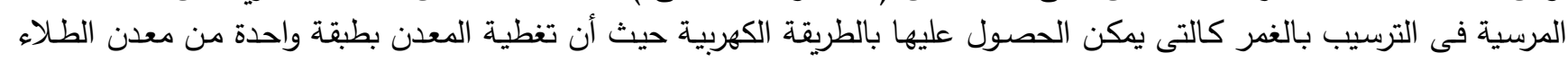
تتهى العملية فورا، وتتميز عملية الترسيب بالغمر بالآتى: - - مقاومة التآكل والأكسدة، وتيزة

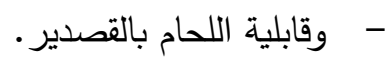

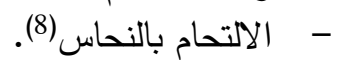
ج- الطلاء بالترسيب الكهربى:

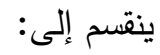

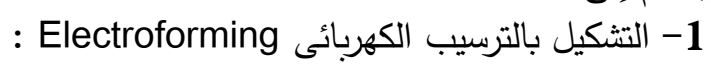

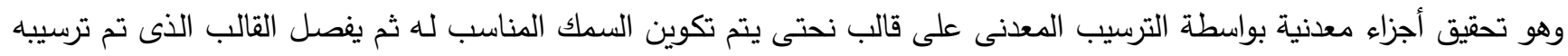

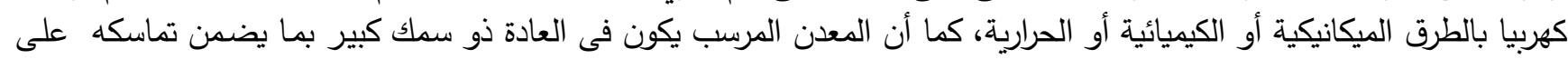

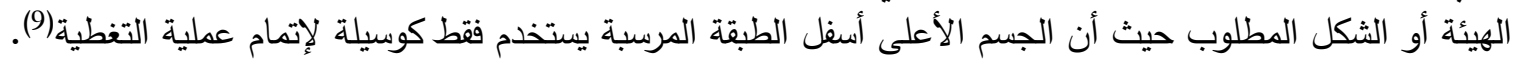

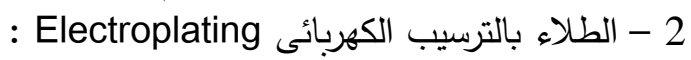

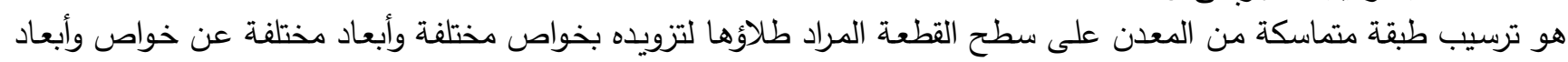

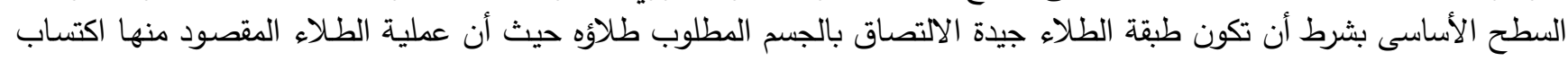
جسم السطح الجديد خواص مختلفة(10). عيوب الطلاء بالترسيب الكهربى الطئ خواصن 1. 2. 3. الالتصاق الضعيف أو الطلاء الملىه بـاءه الثيرات أو الغير منتظم.

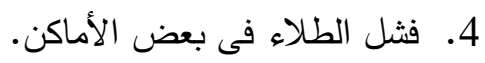
5. 5 . 5دم تجانس الثكل العام للطلاء. 6. وجود نقر في الطلاء.

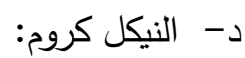

Greenwood J.D.: Heavy Position D.E., Robert Draber, England, 1970. (7) Lee Scoft, Newmen \& Jay Hartely Newmen : Electroforming and Electroplating, New York,, 1979, p.18. (8)

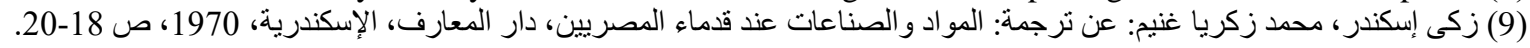
Frank H. Evarts: Hand Book Electroplating, op. cit., p185. (10) 
هو مركب كيميائى ذات خصائص فلزيـة، فعندما تتعرض هذه المـادة إلى الهواء، فإنها تتأكسد بسرعة، فتتكون طبقة خارجيـة من

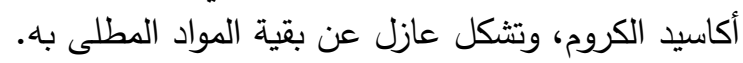

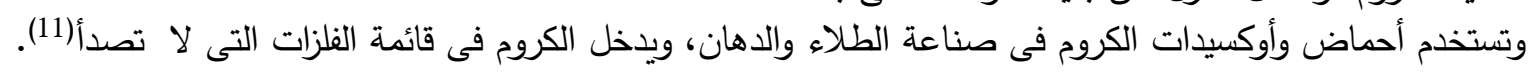
ويمكن تصنيف سبائك النيكل إلى ثلاث فئات التئات: 1

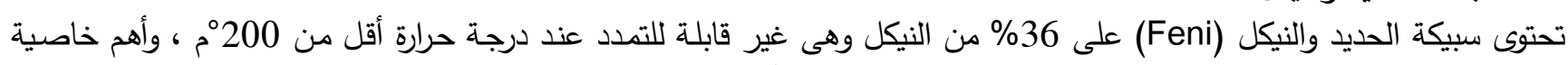

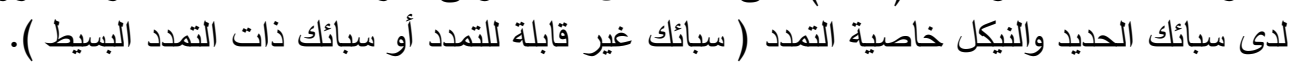
2 - سبائك النحاس والنيكل :

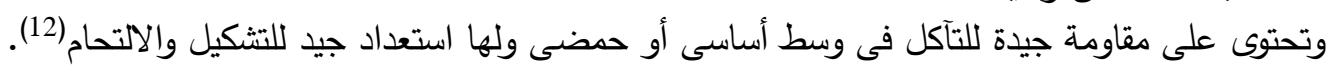

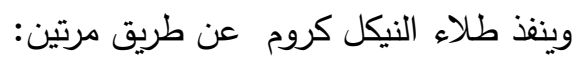

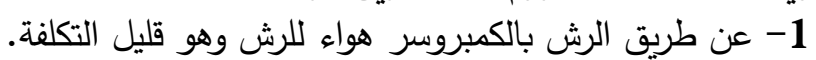

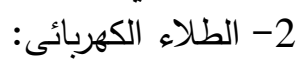

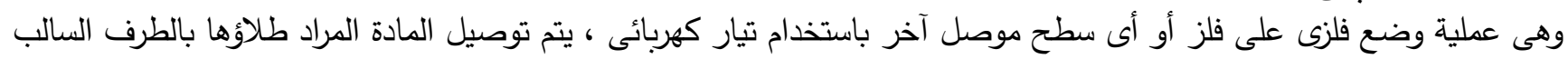

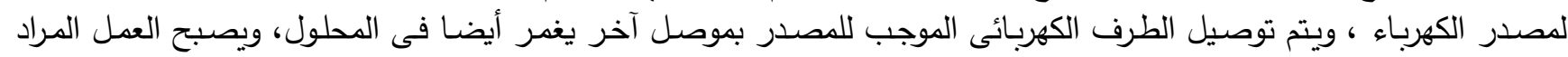

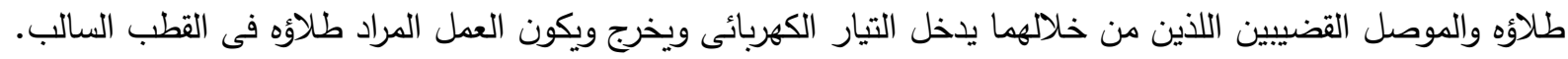

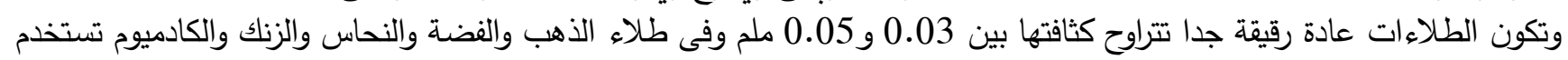

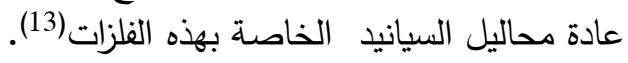
ثانيا: تقنية الطلاء بالأكاسيد:

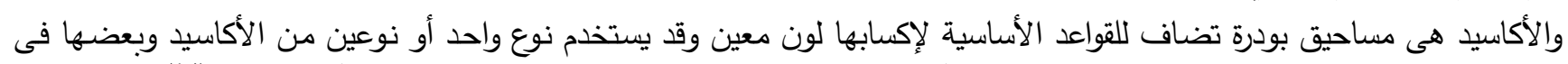

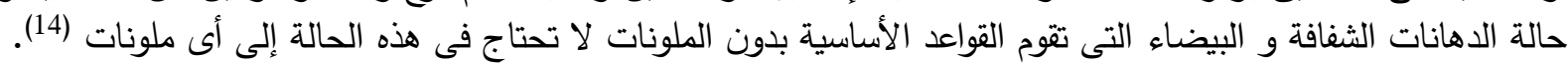

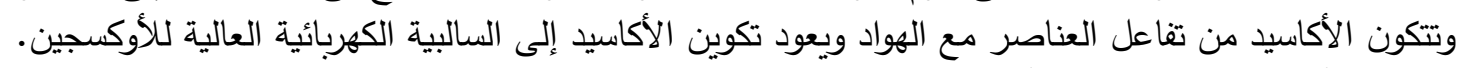

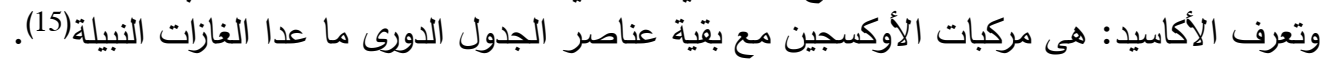
أنواع الأكاسيد:

$$
1
$$

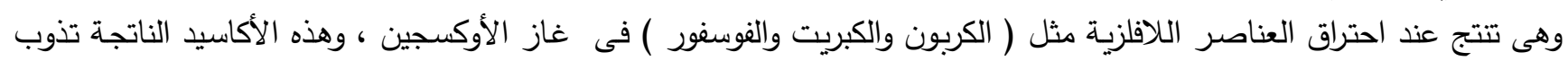

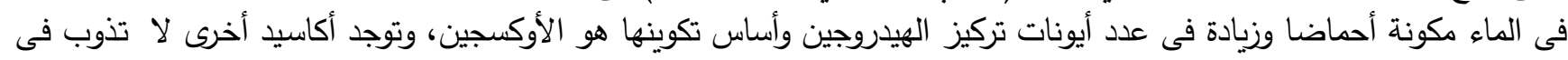

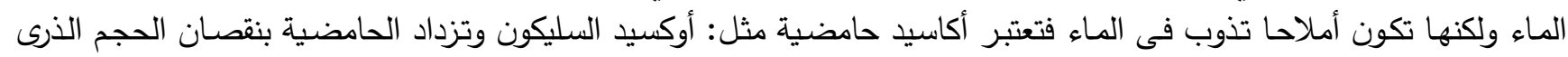
للعنصر المتجدد بالأوكسجين. 2 - أكاسيد قاعدية:

تتتج عند احتراق بعض العناصر الفنزيـة ( مثل الصوديوم والبوتاسيوم والماغنسيوم )، وهذه الأكاسيد الناتجة تذوب فى المياء مكونـة

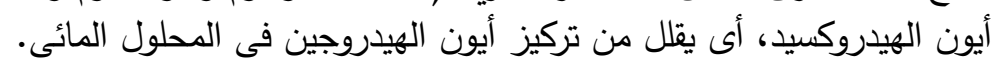

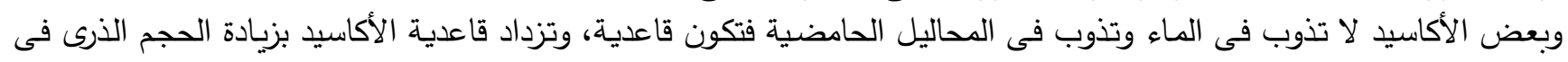

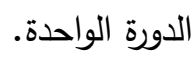

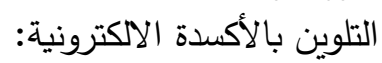
وهذا الأسلوب من شأنه إضافة ألونية ألوانا متعددة وثابتة للمعدن. طرق الحصول على أكاسيد ذات ألوان متعددة:

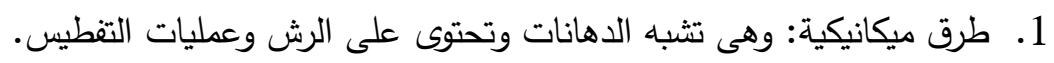

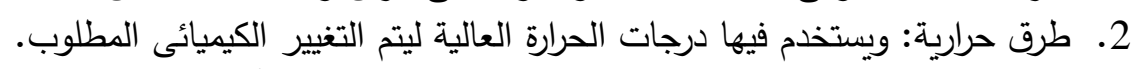

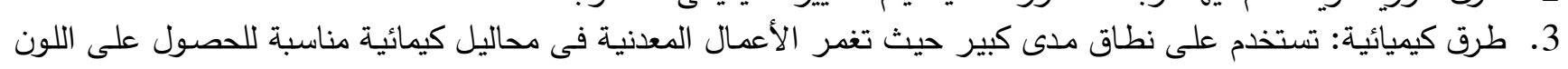
المناسب.

4. طرق الكتروليتية: حيث يكون العمل أسود فى المحلول ثم يؤكسد بعد ذلك(16). 


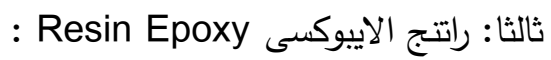

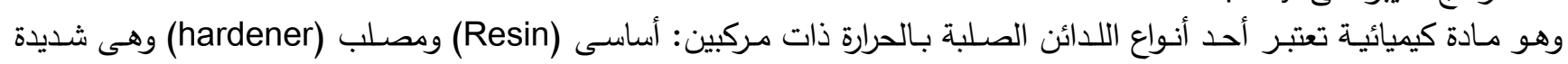

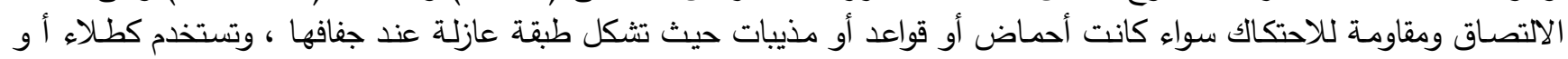
مونة أو لاصق (17). واستخدام الاييوكسى قليل جدا فى مصر وذلك لإتبفاع سعره.

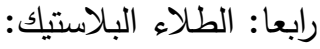

وهو من الدهانات التى قد ثبتت وجودها في الفترة الأخيرة حيث استخدمها بعض النحاتئ التئ في أعمالهم وذلك لما يوفره هذا الطلاء

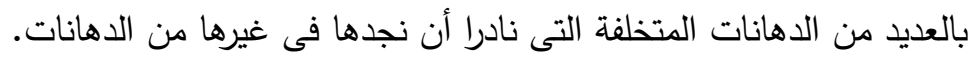

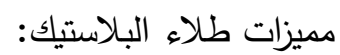

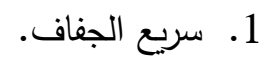
2. 2. يتوافر به العديد من الألوان بالدرجات المختلفة. 3. 3. 2. سعره رخيص. 4. يمكن وضع طبقة فوق الأخرى دون الحاجة للتقشير للطبقة الأولى. 5. 5 5 أناوم للماء.

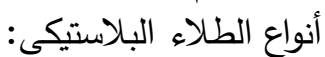

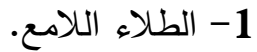
2- الطلاء المطفى. 3- الطعاء. النصف لامع.

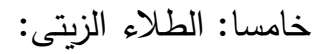
يعد الطلاء الزيتى من أنواع الدهانات التى أثتبت مدى قوتها وأيضا مدى قوة تحملها وقدرتها على مقاومة الماء.

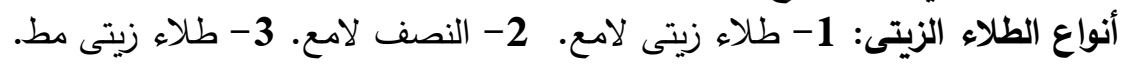

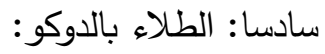
يعد دهان الدوكو الاسم العلمى لدهانات الدان نترو سيلوزية والذى يخفف بالتتر العادى، ويمكن رشها خارج الفرن أو داخل الفرن ، أما

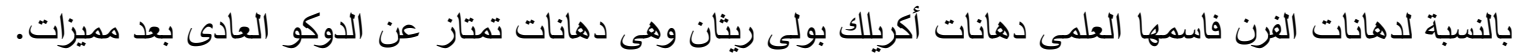

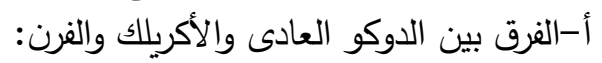
ب - دهانات الدوكو العادية: 1. ـ تصنع الدهانات الدوكو العادية بشكل يدوى وكفاءتها ليست العاديت عالية. 2. ترش الدهانات العادية يدويا عن طريق الكمبروسر .

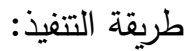
- يمعجن سطح العمل النحتى بالمعجون وينتظر حتى يجف ثم يقوم الفنان بعمل الصنفرة لتسوية السطح وتحديد السوك بالعمل ثم

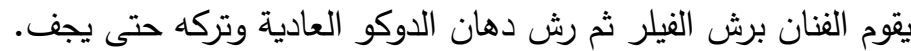

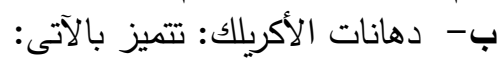

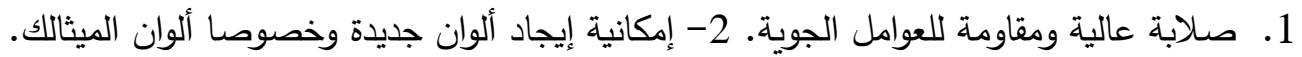

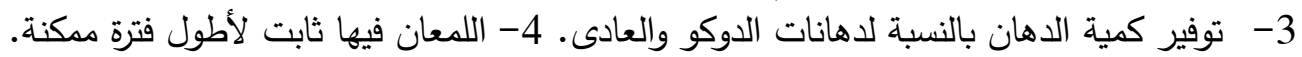

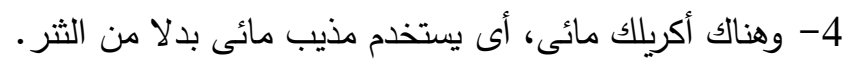

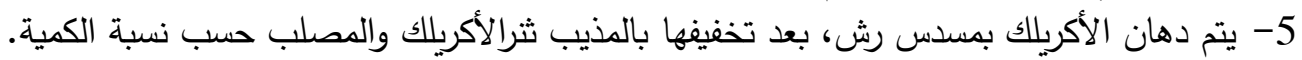

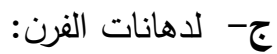
لا يستخدم الفرن الطلاءات مباشرة ولكن يستخدم بدلا منها حبيبات تلتصق على سطح العمل بشكل متساوى ، والفرن له نظام أحواض

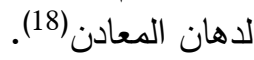
سابعا الطلاء بالذهب: طلى كل من النحاس والفضة بالذهب وذلك عن طالك طريق:

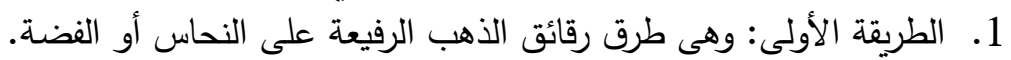
2. لصق أوراق الذهب الرقيقة على سطح النحاس أو الفضة بواسطة مادة لاصنقة. 
وكان يستخدم تقنية الطلاء بالذهب في العصر الفرعونى بكثرة على النحاس فى الأزرار الصغيرة وبعض التهائم والأساور والريش

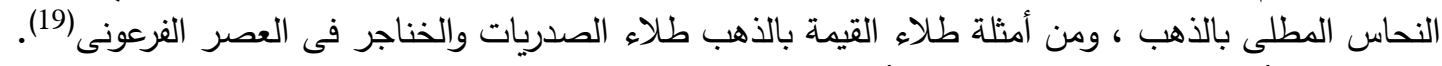

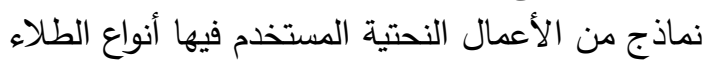

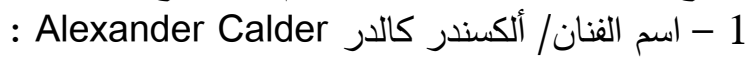

اسم العمل: Tutem

الخامة: رقائق من المعدن والأسلاك الملونة. - نوع الطلاء : دوكو.

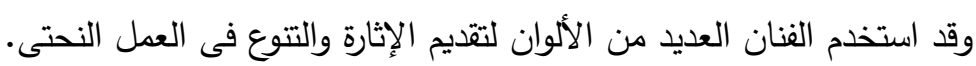

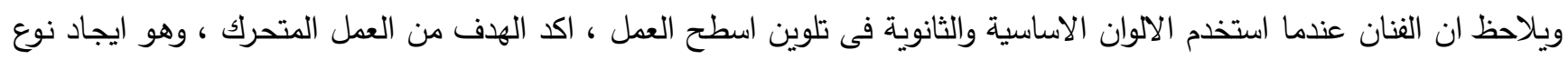
من الديناميكية والتى تؤكدها الالوان الصـاخبة والهادئة ، والتى تعمل على استمرارية تحريك خطوط الرؤية للى المتلقى بين اجذاء

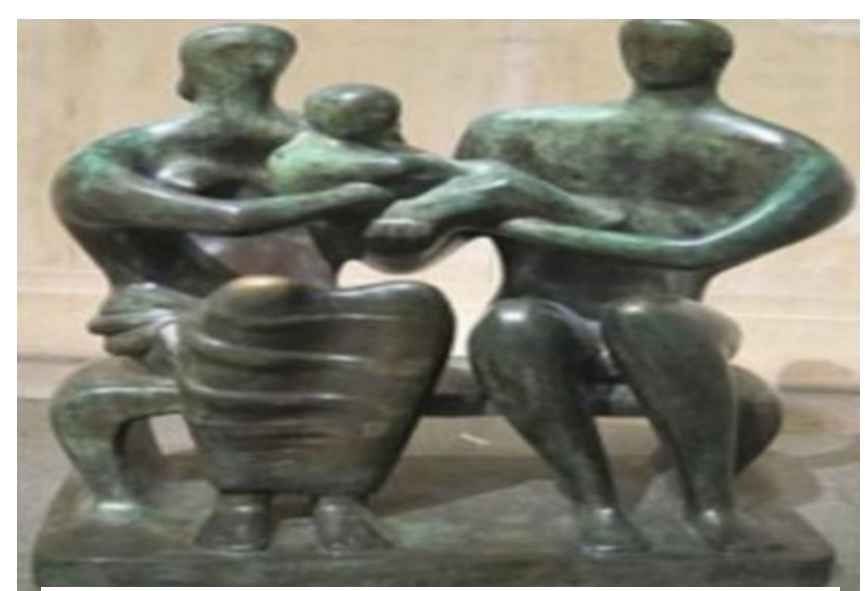

شكل رقم (2) الفنان/ هنرى مور Henry Moore :

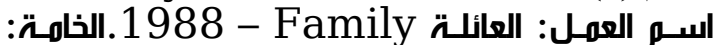
العمل حتى وان كان ساكنا

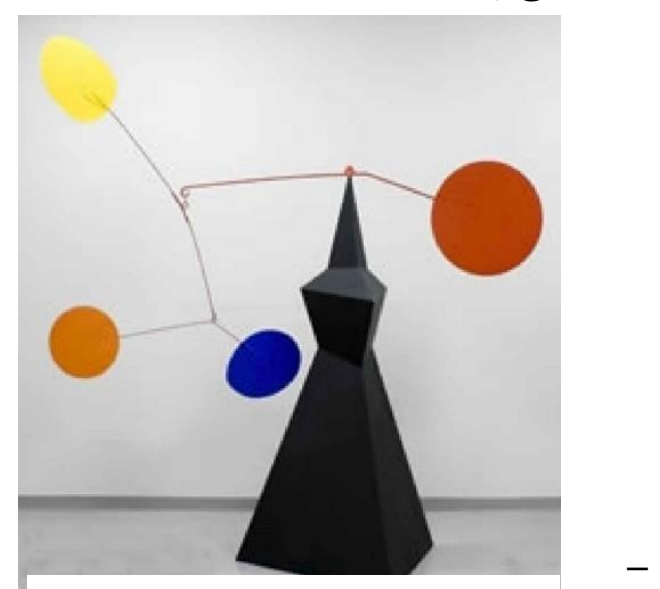

شكل رقم (1) الفنان/ ألكسندر كالار

نوع الطلاء: بتينا اخضر جنزارى.

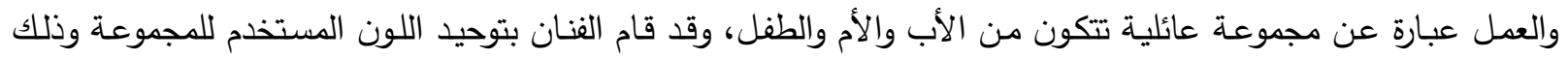

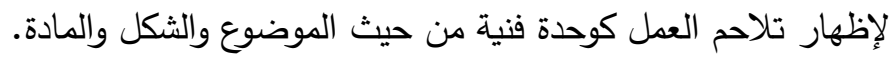

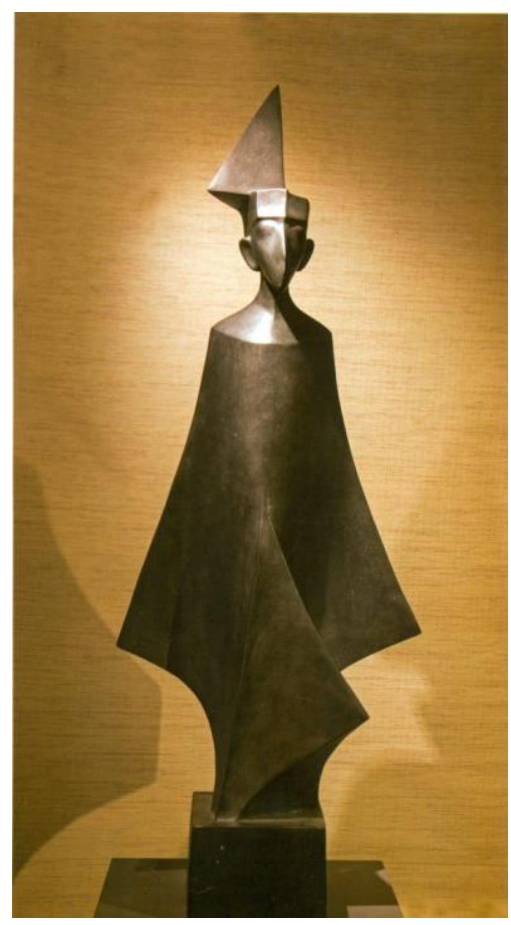
واللون هنا اكد المضمون التعبيرى لها فى الأسرة من تفاهم ووحدة في الروح والفكر

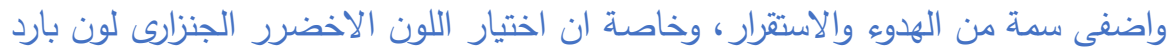
غير مؤجج للعين

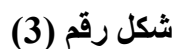

3

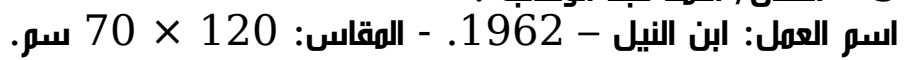
الخاهة: برونز. - نوع الطلاء: بتينا بونيه.

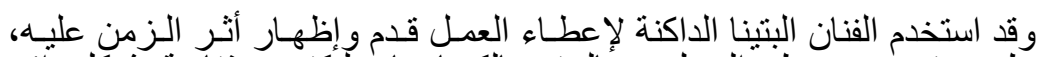

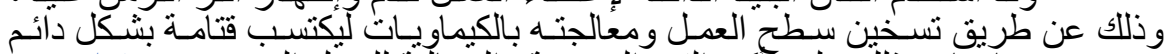

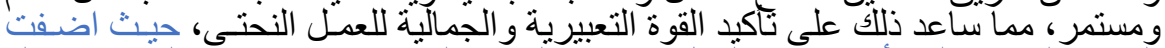

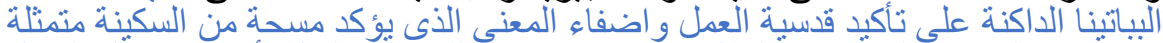

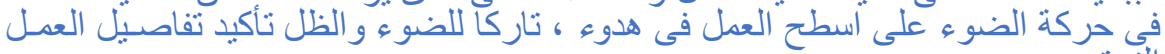

(19) الموارد و الصناعات، ترجمة: كتاب Ancient Egyptian Materials \& in Dustpies ، الطبعة الثانية، 1934، ص 371، 372. 


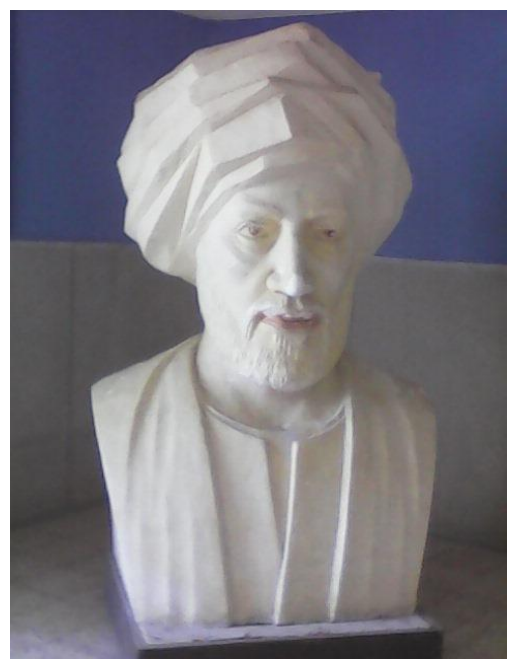

شكل رقم (4)- الفنان/ رأفت منمور:

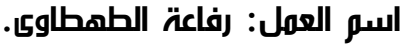

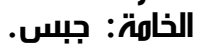

نوع الطلاء : باتينا ترابية على طلاء بلاستيك.

من خلال الطلاء بخامة البلاستيك حاول الفنان الإيحاء بأن العمل منفذ من خامة الحجر

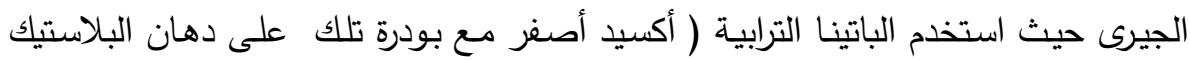
الأبيض ) مما أعطى لخامة الجبس السمات الخارجية لخامة الحجر الجيرى

ويلااحظ ان الفنان حاول اضفاء مسحة من الرصانة والحكمة التى تتسم بها الثخصية

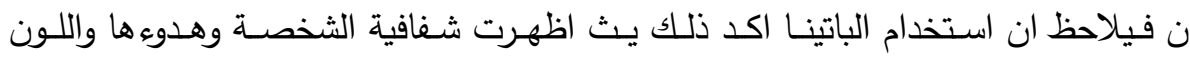
الابيض ينم عن ذلك ، وتوضح مناطق الظل فى العينين والفم وبعض التفاصيل عمق الفكر

وعمق الثخصية

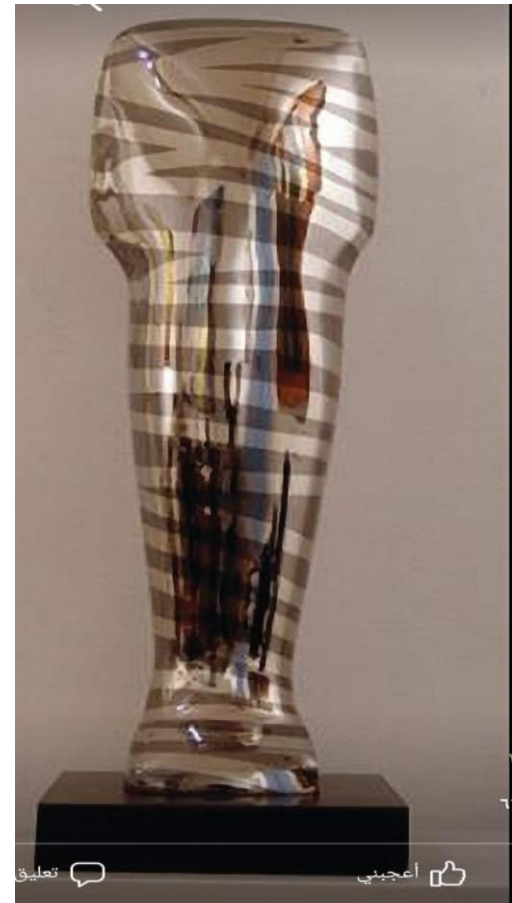

$$
\begin{aligned}
& \text { شكل رقم (5) - الفنان/ ناجى فريد: }
\end{aligned}
$$

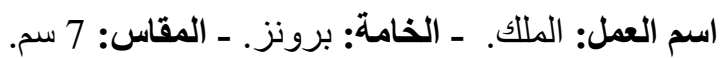

$$
\begin{aligned}
& \text { نوع الطلاء: برونز منكل بنيكل أبيض مع نيكل أسود. }
\end{aligned}
$$

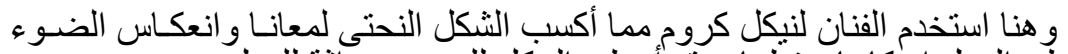

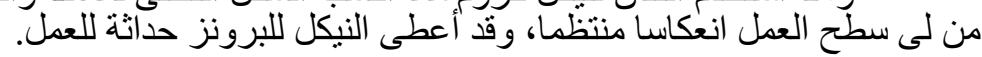

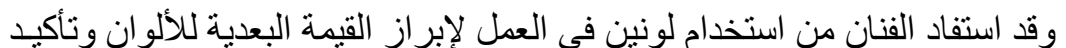

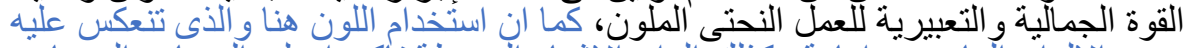

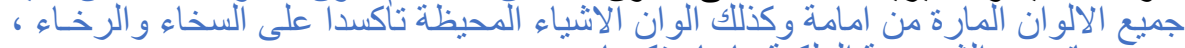
وزخت ماتحويه الثخصية الملكية ماديا وفكريا

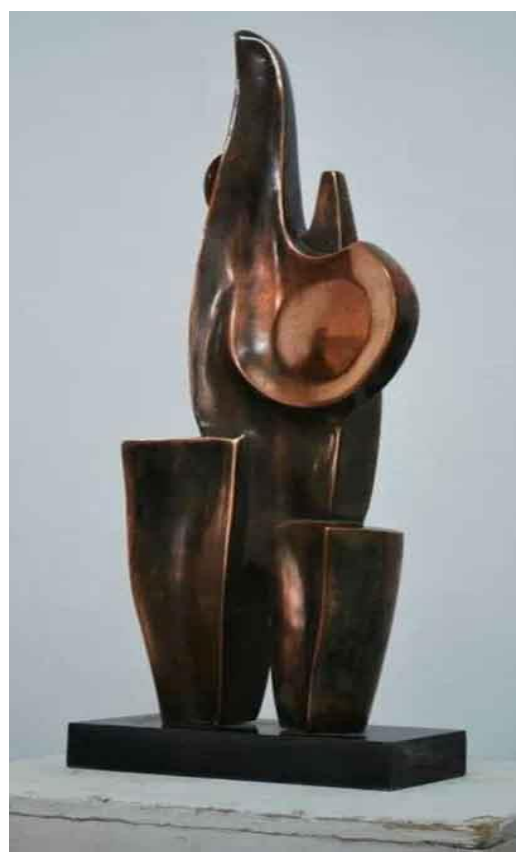

$$
\begin{aligned}
& 6 \text { - الفنان/ على المهبما: } \\
& \text { اسم العمل: فيلة - } 1996 . \\
& \text { المقاس: } 11.7 \text { × } 11.7 \text { × } 22.5 \text { سم. } \\
& \text { الخامة: بولى استر ملون. } \\
& \text { نوع الطلاء: لاكية أحمر . }
\end{aligned}
$$

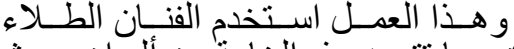

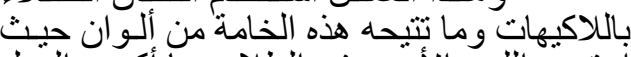

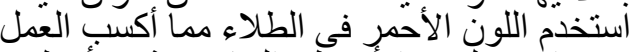

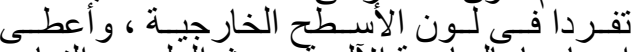

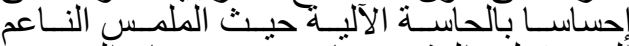

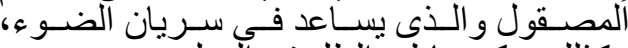

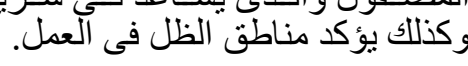

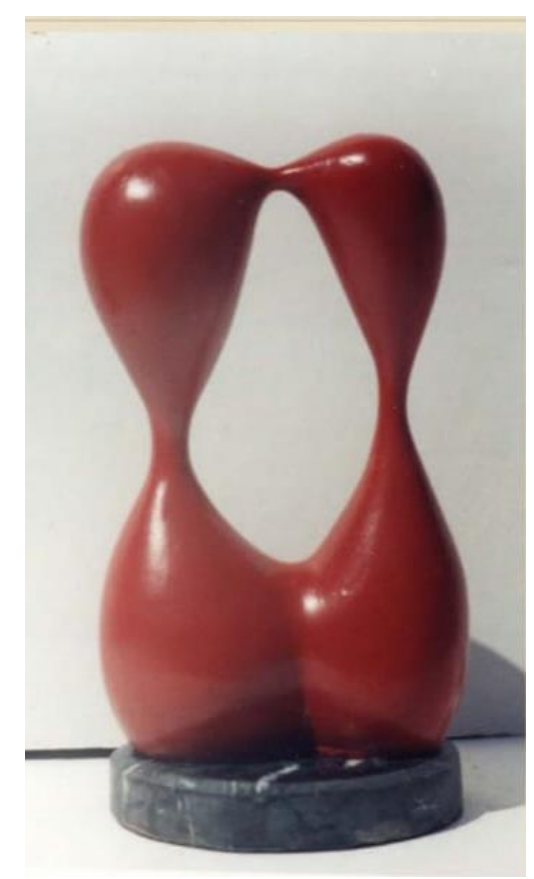

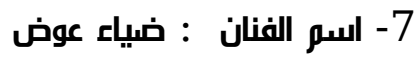

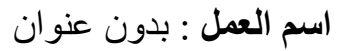

المقاس:60 سم.

نوع الطلاء : نحاس احمر

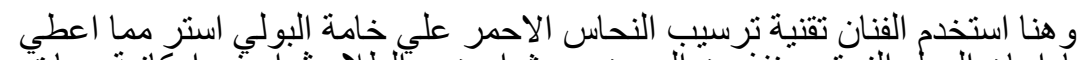

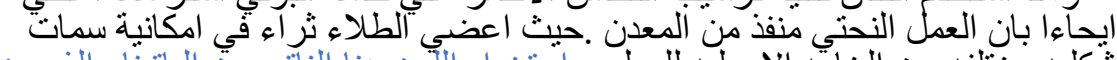

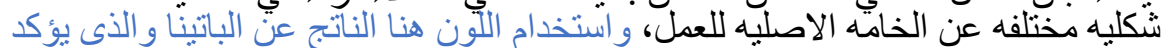

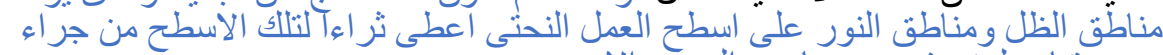
وجود تباين لونى في بعضها عن النور البعض الاخر 


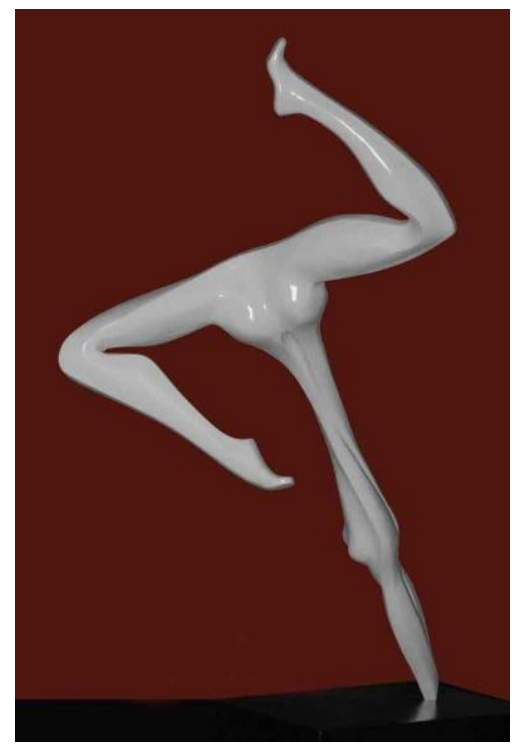

8

اسم العمل: السقوط. ـ الخامة: بولى استر.

المقاس: 85 × 40 × 35 سم. - نوع الطلاء: دوكو أبيض.

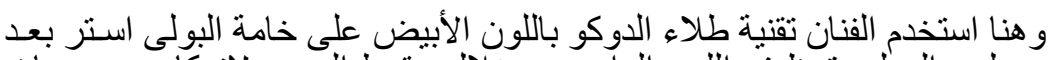

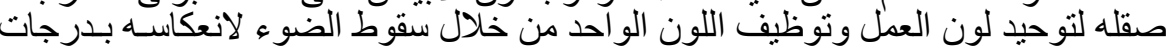

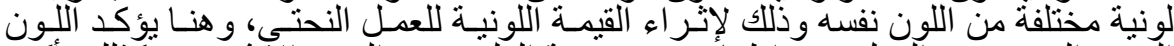

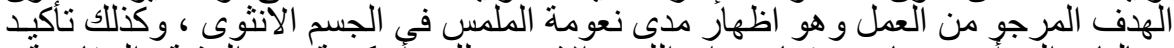

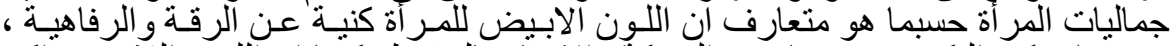

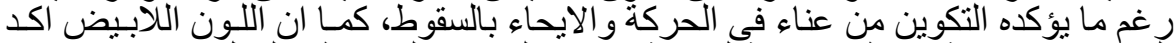

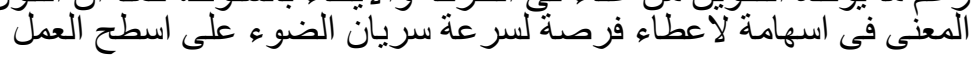

1. استخدام الطلاء وأنواعد فى الأعمال النحتية تأكيد القيم الجمالية والتعبيرية فى العمل

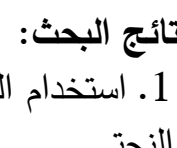
2. تنوع أنواع وأساليب الطلاء الحديثة أعطى للفنان حرية وتتوع فى إنتاج أعماله. 3. أصبح اللون عنصر أساسى فى بعض الطاء الأعمال النحتية المعاصرة.

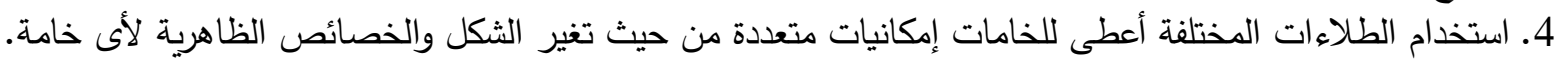
5. يؤثر اللون فى تأكيد أهمية الضوء وسريانه على أسطح العمل النحتى.

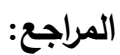

1. روبين جورج كولنجوود: مبادىه الفن، ترجمة: د. أحمد حمدى محمود، الدار المصرية للتأليف والترجمة.

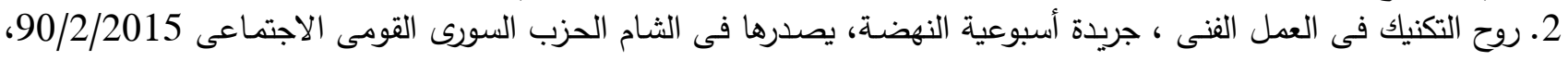
اسم الكاتب: د. حسين، العدد 682. 3. زكى إسكندر، محمد زكريا غنيم: عن ترجمة: المواد والصناعات عندات عند قدماء المصريين، دار المعارف، الإسكندرية، 1970.

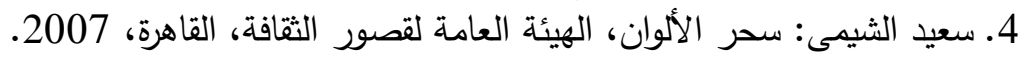

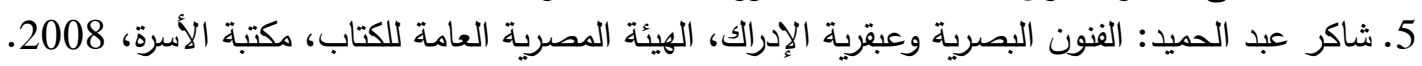
6. الموارد والصناعات، ترجمة: كتاب Ancient Egyptian Materials \& in Dustpies الطبدة الطبعة الثانية، 1934.

\section{المراجع الأجنبية:}

7. Greenwood J.D.: Heavy Position D.E., Robert Draber, England, 1970.

8. Langford, K.E.: Analysis of Electroplating and Related Solutions "Robert Dropar Hd., London, 1962.

9. Lee Scoft, Newmen \& Jay Hartely Newmen : Electroforming and Electroplating, New York, 1979.

10. Moren, John K.: Advanced Composite Mold Making, New York: Van Nostran D., Reinhold co., 1988.

ثالثا: المراجع الاككترونية:

- ar.m.wikipedia.org

- www.bytocom.com

- http://imss.gulpup.com/je.3wi.jpg

-(http://www.gulpup.com/yljach)

- wiki.https://ar.m.wikepedia.org

- https://anouar007.fr.igd

-https://m.alwafd.news 